\title{
Article
}

\section{Determining common contributory factors in food safety incidents - a review of global outbreaks and recalls 2008- 2018}

Soon, Jan Mei, Brazier, Anna Kate may and Wallace, Carol Anne Available at http://clok.uclan.ac.uk/31258/

Soon, Jan Mei ORCID: 0000-0003-0488-1434, Brazier, Anna Kate may ORCID: 0000-0002-1744-1190 and Wallace, Carol Anne ORCID: 0000-0002-1402-2134 (2020) Determining common contributory factors in food safety incidents - a review of global outbreaks and recalls 2008-2018. Trends in Food Science \& Technology . ISSN 0924-2244

It is advisable to refer to the publisher's version if you intend to cite from the work. http://dx.doi.org/10.1016/j.tifs.2019.12.030

For more information about UCLan's research in this area go to http://www.uclan.ac.uk/researchgroups/ and search for <name of research Group>.

For information about Research generally at UCLan please go to http://www.uclan.ac.uk/research/

All outputs in CLoK are protected by Intellectual Property Rights law, including Copyright law. Copyright, IPR and Moral Rights for the works on this site are retained by the individual authors and/or other copyright owners. Terms and conditions for use of this material are defined in the policies page. 


\title{
Determining common contributory factors in food safety incidents - a review of global outbreaks and recalls 2008-2018
}

\begin{abstract}
Background: Global food safety incidents are frequently reported and are on the rise. Although the increase in number of food safety incidents is impacted by improved surveillance and reporting systems and increased awareness from consumers, nevertheless the increase in food safety issues is a threat to public health and the economic costs of countries and businesses. Hence, identifying the root causes of contamination or recall is critically needed to understand the source of contamination in foodborne outbreaks and product recalls, thus helping food businesses to develop risk mitigating strategies.

Scope and Approach: This study aims to identify common contributory factors in food manufacturing incidents leading to potential food safety incidents (e.g. product withdrawals and recalls, food poisoning incidents and legal offences), and to near misses. This study reviews published food safety incidents and recalls collated from official websites (e.g. Center for Disease Control and Prevention, Rapid Alert System for Food and Feed, Food Standards Australia New Zealand) and journal databases (e.g. Science Direct, PubMed). Ishikawa cause and effect analysis was used along with published information to identify possible root causes.
\end{abstract}

Key Findings: The total specific food safety incidents and/or recalls with known or suspected causes found over the period $2008-2018$ is 2932 . Where possible, the contributory and root causes of incidents were identified, or literature evidence was used to determine the suspected cause. Undeclared allergens and cross contamination were identified as the top two recorded causes of food safety incidents/recalls. This review has further proposed the primary and secondary causes for undeclared allergens and cross contamination.

Conclusions: This study offers key insights into global food safety incidents according to food and drink categories, hazards and common contributory factors. Food manufacturers could use the identified primary and secondary causes as guidance for continuous improvement programmes to prevent food safety incidents.

Keywords: cross contamination; hazards; root cause analysis; undeclared allergens

\section{Highlights}

- Food safety incidents were frequently reported in raw fish and ready-to-eat meals.

- Incidents involve all 4 hazard categories (biological, chemical, physical, allergen).

- Cross contamination and undeclared allergens are the most frequently cited causes of incidents.

- Overall causes for incidents were reasonably detailed but there is limited information on root causes.

- Primary and secondary causes for unidentified allergens and cross contamination were proposed. 


\section{Introduction}

Food safety incidents are frequently reported in the food supply chain and numbers are on the rise. A food safety incident occurs when the safety of the food has been compromised and actions are required to protect consumers (FSA, 2019). Examples of food safety incidents include contamination of food products such as the recent South African Listeria monocytogenes outbreak in polony (a local cold meat) (Boatemaa et al., 2019) and deliberate adulteration of food and feed for economic gain e.g. substituting beef with horsemeat (FSAl, 2013). Although the increase in number of food safety incidents is impacted by improved surveillance and reporting systems and increased awareness from consumers, nevertheless the increase in food safety issues is a cause for concern. Foodborne diseases are prevalent globally and are major causes of morbidity and death. Recent estimates revealed norovirus and Campylobacter as the most frequent causes of foodborne illness. Deaths were attributed to non-typhoidal Salmonella enterica, Salmonella Typhi, Taenia solium, hepatitis A virus and aflatoxin (WHO, 2015). Food safety issues often result in food recalls which are a threat to economic cost of businesses and countries.

Recent foodborne disease outbreaks include Listeria monocytogenes in South Africa, which infected 1060 patients of whom 216 died. The outbreak was traced to a ready-to-eat (RTE) processed meat plant where the Listeria outbreak strain was identified in patient isolates, polony and the processing environment (Boatemaa et al., 2019). However, the source of contamination e.g. how the outbreak strain was introduced into the factory and how it was transferred to food products remain undetermined (Whitworth, 2018). Another international listeriosis outbreak in the EU affected 47 patients and resulted in 9 fatalities between 2015 - 2018. Frozen corn was identified as the likely source of outbreak of Listeria monocytogenes serogroup IVb, but matching strains of $L$. monocytogenes were also found in other frozen vegetables (ECDC, 2018a; ECDC-EFSA, 2018). Further investigations were recommended to identify the source of contamination (ECDC, 2018b). These examples highlight the need to determine the root cause of the incidents and why the contamination occurred. Cross contamination of food and beverages can occur at all food processing stages. Nerin, Aznar and Carrizo (2016) reviewed the food processing steps that can contribute to food contamination such as external raw food contamination, during transportation, cleaning processes, heating, food packaging and during food storage. The various sources, routes and contributors of contamination were emphasised by Kase, Zhang and Chen (2017) who reported that contamination events leading to outbreaks could occur before, during and after food processing. Hence, identifying the causes of contamination or recall is critically needed to understand the potential sources and routes of contamination of foodborne outbreaks and product recalls, and to 
develop steps to mitigate their occurrence. To date, there remains limited data on contributory factors associated with food safety incidents; thus further comprehensive review of reported food safety incidents and recalls is needed.

Potter et al. (2012) conducted a review of product recalls in the agri-food industry in the USA, UK and Ireland from 2004-2010. Official sites such as US Food and Drug Administration, US Department of Agriculture Food Safety and Inspection Service, UK Food Standards Agency and Food Safety Authority of Ireland were used. Researchers found that operational hazards (including mislabelling, packaging defects, product contaminations, production defects, unauthorised ingredients, incorrect ingredient level and food fraud) were the most frequent recall type (Potter, Murray, Lawson, \& Graham, 2012). The Rapid Alert System for Food and Feed (RASFF) System is also often reviewed and analysed by researchers to determine, for example, allergen-related recalls (Padua, Moreira, Moreira, de Vasconcelos, \& Barros, 2019), food products contaminated with Listeria monocytogenes (Luth, Boone, Kleta, \& Al Dahouk, 2019), food product notifications' trends (D'Amico et al., 2018), food safety issues (Djekic, Jankovic, \& Rajkovic, 2017; Kleter, Prandini, Filippi, \& Marvin, 2009) and for prediction of food safety incidents (Bouzembrak \& Marvin, 2019) and fraud (Bouzembrak, \& Marvin, 2016). Reviews of RASFF data carried out to date were topic-specific, e.g. focused on specific food safety issues, food and drink categories or affected countries. There is little research that examined the contributory factors and root causes of food safety incidents and lessons learned (Kase et al., 2017). Thus, this study aims to identify common contributory factors in food manufacturing incidents (e.g. incidents resulting in product withdrawals and recalls, food poisoning incidents and legal offences) and near misses by reviewing published food safety incidents and recalls collated from official websites and journal articles and, where possible, to identify the contributory and root causes of the incidents. Where contributory causes are unavailable or unclear from official sources, this study aims to use additional literature evidence to determine the suspected causes, and to organise these in order to provide guidance on potential root causes.

\section{Approach}

A systematic search and review of food recall and food safety incidents was conducted. A systematic search and review process combines the strength of a critical review with a comprehensive search process. It provides a more complete picture of a research topic such as 'what are the contributory factors of food safety incidents' than a systematic review which is limited to randomised controlled trials or intervention studies (Grant, \& Booth, 2009). It does not adhere to a specific guideline, hence this study did not include a quality assessment to determine inclusion/exclusion criteria. Nine 
official websites and five journal databases were reviewed from $2008-2018$ (Table 1). Since the data were collated from governmental websites, this approach ensures data credibility. According to Potter et al. (2012), governmental organisations and their websites provide the most detailed and accurate records of food recalls. The sources were selected based on the quality of data available (where possible with root cause analysis) and their known previous use in desktop research for product recalls and incidents (Bouzembrak, \& Marvin, 2016; Luth et al., 2019; Tähkäpää et al., 2015). Apart from Rapid Alert System for Food and Feed (RASFF), each site was reviewed from 2008 to October 2018. Journal articles were reviewed where possible to identify known or suspected causes of outbreaks or contamination. Journal databases i.e. Science Direct, Ingenta Connect, Emerald Insight, PubMed and Google Scholar were searched online from 2008 - 2018. Search terms included 'foodborne outbreaks', 'food source', 'causes', 'investigation', 'root cause', 'contamination', 'microbiological', 'chemical', 'physical', 'food allergen' and 'food fraud'.

Data collected included affected products, food and drink categories, type of food hazards, details of the incident (if provided), origin, distribution, number of injuries and deaths. Food safety hazards were divided into biological (e.g. microorganisms), chemical (e.g. natural toxins, antibiotics), physical (e.g. metal, plastics) and allergen (e.g. fish, egg, tree nuts) categories. Data were screened and triangulated with similar websites and research articles to ensure repeated records were not duplicated. Random search validation by the first and second author was also carried out to ensure accurate data were recorded.

Data were extracted and transferred to Microsoft Excel 2010 to create descriptive statistics and frequency distributions. A Chord diagram was constructed using https://app.flourish.studio/ in Figure S1 to visualise the inter-relationships between food and drink categories with hazards and contributory factors. Food and drinks were divided into 18 categories according to the BRC Global Standard for Food Safety (BRC, 2015) i.e. raw red meat (e.g. beef, veal, pork), raw poultry (e.g. chicken, turkey, duck), raw prepared products (e.g. comminuted meat and fish products, ready-tocook meat, vegetable prepared meals), raw fish (e.g. wet fish, molluscs, crustacea), fruit, vegetables and nuts (e.g. herbs, unroasted nuts), prepared fruit, vegetables and nuts (e.g. semi-processed or prepared foods, chips, frozen vegetables), dairy and liquid egg (e.g. milk, yogurt, and including nondairy products such as soya milk), cooked meat and fish products (e.g. meat and fish pâté, hot smoked fish, poached salmon), raw cured/and/or fermented meat and fish (e.g. salamis, air-dried meats, dried fish), ready-to-eat meals (e.g. chilled foods, wraps, pizzas), cans and jars (e.g. beans, soups, sauces), beverages (e.g. non-alcoholic drinks, concentrates, cordials), alcoholic drinks (e.g. 
beers, wine, spirits, vinegar), bakery (e.g. breads, cakes, biscuits), dried foods (e.g. spices, rice, pasta), confectionery (e.g. candies, chocolate, jellies), cereal and nuts (e.g. oats, muesli, roasted nuts) and oils and fat (e.g. margarine, shortening, spreads). Fishbone diagrams (Ishikawa, 1990) were used to organise and visualise the contributory factors and root cause analysis of the two main reported causes of incidents and recalls. Ishikawa cause and effect analysis was used to identify possible root causes by asking questions such as 'What happened?', 'When?', 'Where?', 'Why?' and 'How?' (Ishikawa, 1990; Wallace and Motarjemi, 2014). The Ishikawa diagram helps to illustrate the sequence of events that leads to an incident. The incidents depend on many factors that can be divided into groups such as materials, machinery, manpower, management, methods and environment (Ishikawa, 1990). This tool has been utilised in food industry to analyse potential hazards at all processing stages (Varzakas, 2016), in construction and manufacturing industries to identify cause of accidents (Hola, Nowobilski, Szer \& Szer, 2017) and in health facilities to improve overall healthcare services (Colli et al., 2019). The possible root causes in this study were also supplemented by literature searches.

Insert Table 1 here

\section{Findings and Discussion}

The total food safety incidents and/or recalls with known or suspected causes reviewed is $\mathbf{n = 2 9 3 2}$. This total is captured from the data sources shown in Table 1, except data from RASFF ( RASFF data is summary reporting and does not give details of individual incidents so known/suspected causes are not available). The total number of incidents from RASFF ( $n=5982)$ is included in food and drink categories (Figure 1a) and in the year category (Figure 2 ) to give an overall picture of the scale of food incidents reporting.

\section{Food safety incidents and/or recalls according to food and drink categories}

Raw fish has the highest number of reported food safety incidents/recalls in this timeframe. RASFF reported the highest number of notifications for raw fish including crustaceans, bivalve molluscs and cephalopods $(n=1,411)$. These notifications included detection of foodborne pathogens (e.g. Listeria monocytogenes, Salmonella spp., Vibrio parahaemolyticus, V. cholerae, norovirus), presence of prohibited substances (e.g. chloramphenicol, nitrofuran), heavy metals (e.g. mercury, cadmium), undeclared or high sulphite content and other allergens and poor temperature control. D.Amico et al. (2018) conducted a comprehensive review of seafood notifications in RASFF that indicated the 
main hazards associated with the notifications. Fish and fish products were identified as the product category with the highest number of notifications, mainly due to non-compliant presence of mercury, cadmium or both, as reported in Nepusz, Petroczi and Naughton (2009) and Piglowski (2018). It is known that seafoods generally bioaccumulate heavy metal contaminants (Bonsignore et al., 2018). Heavy metals including other chemical contaminants such as persistent organic pollutants are often discharged into the marine environment via anthropogenic activities and then accumulate in fish tissues (Traina et al., 2019). Other seafood notifications identified by D.Amico et al. (2018) were caused by poor and inadequate controls such as poor temperature control and lack of hygiene, contamination with pathogenic microorganisms, biotoxins and parasitic infestations.

Ready-to-eat meals recorded the second highest number of incidents/recalls. Some of the most common hazards contributing to the incidents were Listeria monocytogenes, undeclared allergens and contamination with extraneous materials. Other important categories in terms of number of incidents/recalls were fruits, vegetables and nuts, where microbiological hazards such as Salmonella spp. and Escherichia coli and chemical hazards such as chlorpyrifos and formetanate (insecticides) and mycotoxins were some of the hazards commonly found. Our findings on Salmonella spp. in fruits, vegetables and nuts were supported by Da Silva Felicio et al. (2015) who identified raw leafy greens and Salmonella spp. as the top food/pathogen combination, followed by bulb and stem vegetables/Salmonella spp. and tomatoes/Salmonella spp. in ready-to-eat unprocessed foods of non-animal origin. When RASFF data were excluded from the food incidents reporting, a different trend emerged. Ready-to-eat meals, raw prepared products and bakery were identified as the food categories with the highest notifications (Figure 1b). The main contributory factors identified in the top three food categories were undeclared allergens, cross contamination and GMP failures. This is further discussed in the 'Food safety incidents / recalls according to known or suspected causes' section.

Insert Figures 1a and $1 \mathrm{~b}$ here

\section{Food safety incidents and/or recalls from $2008-2018$}

Insert Figure 2 here

There was a 50.2\% rise in total numbers of reported food safety incidents in 2014 compared to 2013 (Figure 2). One of the reasons supporting the spike was a change in the reporting system of the 

(Jan - June), with no data published between the second half of 2011 - 2013. From 2014 onwards, the reporting system was more structured with background information, number of illnesses and related recalls. The improved reporting system from CFIA boosted the numbers from 2014 onwards. Whilst this may not have been the only reason for the apparent jump in numbers between 2013-14, it can be postulated that a smoother rise may have been seen if CFIA data had been published between second half of 2011 and 2013, although this cannot be determined. Only 295 incidents / recalls were noted in 2018 and this total does not include data from RASFF. For the period 20082017 there is an approximate doubling of the annual rate of incidents but some of this increase will be due to the aforementioned change in reporting systems.

The rise in total incidents or recalls is also due to improved surveillance and reporting systems in other countries and networks. For example, the Foodborne Diseases Active Surveillance Network (FoodNet) is an active surveillance system that links 10 state and local health departments with the Centers for Disease Control and Prevention (CDC). FoodNet actively collects data from local physicians and clinical laboratories on the incidences of nine pathogens commonly transmitted through food in the 10 US states covering approximately 15\% of the US population (Crim et al., 2015; FoodNet, 2018). Passive surveillance such as the National Notifiable Diseases Surveillance System (NNDSS) also collects, analyses and summarises data on infectious and non-infectious conditions including foodborne outbreaks (McCabe-Sellers, \& Beattie, 2004; NNDSS, 2018). Similarly, RASFF is an open access tool initiated in 32 countries of the EU and European Economic Area (EEA) to provide information on food safety issues among its members. RASFF notifications received from national food safety authorities are verified by the European Commission and then shared efficiently between its members. RASFF continues to evolve to improve its notifications and reporting system to prevent food safety risks to consumers (Luth et al., 2019; RASFF, n.d.a). Shared collaborative efforts in such regions to record and monitor food safety incidents have contributed to the increased number of reported incidents and recalls.

Food safety incidents and/or recalls according to hazards Insert Figure 3 here

Allergens (46.18\%) are recorded as the top food safety hazard category, followed by microbiological hazards (40.11\%). Key physical hazards (9.31\%) were plastic, metal and glass while chemical hazards (2.25\%) include biotoxins, unapproved ingredients, heavy metals and antibiotics. The 'other' 
category $(2.15 \%)$ includes hazards associated with packaging (e.g. loss of seal integrity, risk of bursting), mislabelling and product tampering (Figure 3).

Allergens

252

Most incidents / recalls were due to undeclared allergens especially milk (24.37\%), multiple allergens (23.93\%) and wheat/gluten (9.97\%) (Figure 4). Bakery (20.30\%), confectionery (17.27\%), and dried foods (13.94\%) were reported as the most common food categories associated with undeclared milk while RTE meals $(26.85 \%)$, bakery $(21.60 \%)$ and raw prepared products $(12.93 \%)$ contain the highest frequency of multiple undeclared allergens. These findings support Gendel and Zhu (2013) who reported that food allergen labelling problems are the most common cause of recalls for US FDA regulated food products. Milk was the most frequently undeclared allergen and bakery products were the main food products recalled (Gendel \& Zhu, 2013). Bedford, Yu, Wang, Garber and Jackson (2017) tested a selection of dark chocolate bars for undeclared milk and found $87 \%$ of the chocolate products ( $n=23$ ) with an advisory statement (e.g. may contain) for milk contained milk at more than $100 \mathrm{ppm}$ whilst more than half were above $1000 \mathrm{ppm}$. Fifteen percent of the chocolates with dairy-free or lactose-free statement and $25 \%$ of vegan chocolate were also tested positive for milk. Bedford et al. (2017) further supports our findings that milk was the most frequently undeclared allergen. In RASFF, cereals and bakery products were the most reported food categories and milk, cereals containing gluten and eggs were the main allergens in allergen-related recalls between 2011 - 2017. The notifications were mostly triggered by a 'company's own check' (company notifying an outcome as a result of their own testing or quality assurance measures) and 'official control on the market' (official control on the European Economic Area internal market, e.g. official samples tested by government bodies) (Padua et al., 2019; RASFF, n.d.b). There was also a distinct increase in notifications between 2014 and 2015 and this may be related to the implementation of Regulation (EU) No 1169/2011 on provision of food information to consumers in December 2014 (Padua et al., 2019; Regulation EU No. 1169/2011) which has particular relevance for accurate food allergen labelling. Similarly, in microbial notifications in RASFF, the practice of making food manufacturers accountable for the detection and notification of contaminated products can help to reduce the number of contaminated food products entering the market (Luth et al., 2019). Insert Figure 4 here

\section{Microbiological hazards}


The main microbiological hazards include Listeria monocytogenes (32.91\%), Salmonella spp.

(29.85\%) and E. coli (17.86\%) (Figure 5). Listeria monocytogenes was often reported in RTE meals (31\%), cooked meat \& fish (16.80\%) and dairy \& liquid eggs (14.47\%). Fruits, vegetables and nuts (18.23\%) and dried foods (16.24\%) were associated with Salmonella spp. while E. coli were found in raw prepared products (34.29\%) and raw red meat (31.43\%).

L. monocytogenes is environmentally ubiquitous and can survive and grow in hostile conditions such as refrigeration temperature, low $\mathrm{pH}$ and high salt concentration. Certain RTE foods such as delicatessen meats, poultry products, seafood and dairy products are high-risk vehicles for $L$. monocytogenes as these foods tend to be chilled and provide a suitable environment for $L$. monocytogenes to grow (Gandhi \& Chikindas, 2007; Swaminathan, Cabanes, Zhang, \& Cossart, 2007). Listeriosis outbreaks in the EU were linked to seafood, dairy, meat and vegetable products (EFSA, 2015). A recent report by Luth et al. (2019) found that the majority of L. monocytogenes notifications in Germany from 2001 - 2015 were associated with milk (especially soft cheese), fish and meat products. However, listeriosis outbreaks were recently associated with unconventional food vehicles such as fresh produce (e.g. celery, cantaloupe, mung bean sprouts, stone fruits, caramel apples) and ice cream in the US (Buchanan, Gorris, Hayman, Jackson, \& Whiting, 2017).

Fresh produce, nuts and dried foods have been linked to microbiological outbreaks in many parts of the world (Julien-Javaux, Gerard, Campagnoli, \& Zuber, 2019; Russo et al., 2013; Werber et al., 2005). A review of US FDA recalls between $2002-2011$ found that nuts and edible seeds, seafood and spices were commonly recalled due to microbiological contamination especially Salmonella (Dey, Mayo, Saville, Wolyniak, \& Klontz, 2013). Another review carried out between $2012-2017$ in US for the fresh fruits and vegetables product category reported that the most common reason for recalls was the presence (or possible presence) of L. monocytogenes and Salmonella spp. (Paramithiotis, Drosinos and Skandamis, 2017).

Salmonella spp. and other pathogenic bacteria are often found in livestock, pets, wild animals, animal manure and contaminated irrigation water, making it more likely that the organism will contaminate fresh produce at the pre-harvest stage (Matthews, Sapers, \& Gerba, 2014; Jacobsen \& Bech, 2012). The ability of Salmonella to withstand desiccation conditions and survive for long periods of time under low $A_{w}$ conditions (Lambertini et al., 2016) make this a pathogen of concern in 
low water activity foods such as chocolate (Werber et al., 2005), peanut butter (Sheth et al., 2011), nuts (Uesugi, Danyluk, \& Harris, 2006) and spices (Keller, VanDoren, Grasso, \& Halik, 2013).

E. coli is a naturally occurring bacteria found in the gastrointestinal tract of cattle. During slaughter and processing, cross contamination of the originally sterile muscle tissues occurs, resulting in contaminated beef and beef products (Cassin, Lammerding, Todd, Ross, \& McColl, 1998; Yang, Wang, He, \& Tran, 2018). Pathogenic E. coli is a major cause of outbreaks and is often associated with consumption of raw or undercooked, contaminated beef (CDC, 2018a; Gaulin, Ramsay, Catford, \& Bekal, 2015; Yahata et al., 2015).

It is interesting to note that there were very few Campylobacter incidents (with known/suspected causes) reported in most of the databases. Campylobacteriosis remains the most commonly reported zoonosis and foodborne illness in the EU (EFSA, 2018; Lake et al., 2019). Similarly, it is a leading cause of foodborne illness in the US (CDC, 2018b). Previous source attribution studies identified chicken and poultry meat as major risk factors for Campylobacter infections (Batz et al., 2012; Domingues et al., 2012; Ravel et al 2017). Note that Figure 5 excludes data from RASFF which covers the Europe region.

Insert Figure 5 here

\section{Food safety incidents / recalls according to known or suspected causes}

2932 specific food safety incidents/recalls (not including RASFF summary data) were recorded in Figure 6. Each incident was reviewed to identify (where possible) the cause of the food safety incident or recall. Where causes were given, a qualitative viewing of the data allowed further detail on contributing factors to be listed. In addition, some of the causes (with no contributing factor identified) were cross-referenced with scholarly and research articles to identify plausible specific sources of contamination.

Undeclared allergens (40.45\%) were the highest recorded cause of food safety incidents/recalls. Cross contamination (28.58\%) of food products with microbiological hazards (especially cross contamination from farm for fresh produce and raw milk, cross contamination of raw meat during slaughter or from processing site and cross contamination from the processing environment in raw prepared products and RTE meals) was the second highest reported cause of incidents. GMP failures $(9.17 \%)$ include insanitary design, lack of maintenance and equipment failure (leading to 
contamination), ineffective segregation of raw and finished products, improper cleaning practices and lack of monitoring of sanitation conditions and staff hygiene.

Insert Figure 6 here

Incoming material control (7.64\%) is another cause for concern as a number of incidents/recalls were linked, a typical example being the 2008-09 Peanut Corporation of America (PCA) multistate Salmonella Typhimurium incident in the USA, where 714 people were affected (CDC, 2009). There were multiple causes at the PCA manufacturing site, including GMP failures and cross contamination and possibly processing issues. However, any supplier who initiates a product recall will trigger a series of product recalls by its customers (food manufacturers or retailers) and thus result in incoming material control incidents for those manufacturers. The process failure category $(5.42 \%)$ includes specific causes such as process deviation, undercooking, temperature abuse during processing and swelling and bursting of packaging materials (due to microbial growth). Mislabelling (4.23\%) was identified as one of the contributing factors for undeclared allergens but was also listed as a cause in its own. Mislabelling occurred when manufacturers incorrectly labelled ' $X$ ' food product as ' $Y$ ' and there was no declaration of allergens for product ' $X$ ', or where incorrect use-by date or incorrect cooking instructions were applied to the product.

Product formulation (1.64\%) also contributed to undeclared allergens. Changes in an ingredient formulation by the supplier or manufacturer without a corresponding change in the finished product label was the major cause noted in this category. Packaging deformity, integrity issues and caps popping off unexpectedly were some of the causes identified under packaging control (0.78\%). Food fraud $(0.55 \%)$ includes illegal sales of recalled or unsafe products and stolen goods.

Equipment design (0.51\%) has been categorised on its own due to the identification of causes carried out in some incidents. Equipment design failures were caused by broken or dislodged metal or plastic pieces from processing machines, conveyor belts, guiding rods and reels used to move the belt. Natural contaminants $(0.44 \%)$ are naturally occurring chemicals found in food products such as cyanide, marine biotoxins and heavy metals in fish. Needles, nails, medications (pain relief tablets), unknown powder and a battery were some of the hazards found in malicious/tampering $(0.27 \%)$ attack of food products. There were four incidents of unknown causes (0.31\%), e.g. 'a taint'; however, the lack of information prevented the identification of a plausible cause for each of the four examples in this category. 
Undeclared allergens and cross contamination affected a diverse range of food and drink categories

(Figure S1). The remainder of this study will focus on these two main causative factors as most food and drink categories were affected by them.

\section{Undeclared allergens}

Most incidents / recalls associated with allergens were listed as undeclared allergens. This is still a vague description of the cause although some manufacturers further identified the issue as not declaring the allergen in English or the allergen was declared in uncommon terms. For example, a manufacturer declared cashews with a French term 'anacardes' that is not commonly recognised in Canada (CFIA, 2008). Ingredient statement omission is another factor particularly when the ingredients used are less conspicuous such as icing (that contains egg) in a cereal based product (CFIA, 2010), glaze (that contains wheat) used in nuts (USDA FSIS, 2017) or if food products containing multiple small packs of ingredients e.g. seasoning ingredients were left off the ingredients list (USDA FSIS, 2016). Errors in a newly designed label where an incorrect ingredient statement was used reiterate the need for verification of new labelling artwork (FSN, 2014).

Bucchini, Guzzon, Poms and Senyuva (2016) agreed that 'not indicated on the label' as a generic explanation of cause and does not indicate why the failure occurred. However, the authors did find that a small percentage of the products were recalled due to unintended presence of allergen as a result of cross contact. In the US, the use of wrong package or label was identified as the most frequent problem leading to food allergen recalls (Gendel \& Zhu, 2013). Other problems that caused the allergen recalls were also identified and categorised. For example, computer error (e.g. use of wrong computer file leading to labelling error), cross contact (e.g. ineffective cleaning between products with different allergens), in process error (e.g. unfinished product added to another product without the allergen), ingredient mislabelled (e.g. ingredient used to manufacture the product did not declare the presence of an allergen) and knowledge (e.g. manufacturer unaware of allergen labelling requirements) (Gendel \& Zhu, 2013). Although one could summarise that the major factors for undeclared allergens were ingredient statement omissions and errors, cross contact from food processing equipment and errors caused by ingredient suppliers or food processing staff (Vierk, Falci, Wolyniak, \& Klontz, 2002), the root causes for the omission, cross contact, errors by suppliers and unclear supply chain information transfer remain unknown.

\section{Cross contamination}


Cross contamination, especially from microbiological hazards, could be further classified into cross contamination at pre-harvest and processing stages. There were more extensive reports provided for cross contamination incidents especially if the contamination resulted in microbiological outbreaks. However, publication of the findings of traceback investigations is still limited. Investigators were able to trace Salmonella Saintpaul in agricultural water and raw produce on a Mexican farm and jalapeño peppers in Texas (Behravesh et al., 2011) while Escherichia coli 0157:H7 in bagged spinach was linked to wild boars, cattle and irrigation water (Gelting, Baloch, ZarateBermudez, \& Selman, 2011). In the listeriosis outbreak associated with cantaloupes, McCollum et al. (2013) traced Listeria back to environmental and product samples in the packaging facility but environmental samples from growing fields were negative. Some of the key factors identified as the most likely cause of contamination of cantaloupes with Listeria monocytogenes were contamination from a truck used to transport waste culled cantaloupes to a cattle farm. The truck was found parked next to the packing facility and could have introduced contamination into the facility. Facility design that allowed stagnant water to accumulate on the packing facility floor and inadequate good manufacturing practices (GMP) may also have contributed to the contamination (McCollum et al., 2013; US FDA, 2011).

To date, there has been an increase in foodborne disease outbreaks associated with consumption of raw and/or minimally processed fruits and vegetables. Recent outbreaks include E. coli O157:H7 in romaine lettuce (CDC, 2019c) and alfalfa sprouts (CDC, 2016), E. coli O157:H7 in mixed salad leaves (PHE, 2016) and Salmonella Hvittingfoss on rock melons (Flynn, 2016). Sources and established contamination routes of pathogens include agricultural inputs such as contaminated irrigation water, inadequately composted manure, contaminated water used in reconstituted pesticides, soil, livestock, wild animals (including insects) and the ability of microorganisms to colonise and persist in fresh produce (Alegbeleye, Singleton, \& Sant'Ana, 2018; Verhaelen, Bouwknegt, Rutjes, \& Husman, 2013; Wasala, Talley, DeSliva, Fletcher, \& Wayadande, 2013; Erikson et al., 2019).

Listeria monocytogenes remains a major challenge for ready-to-eat food, cooked meat and fish products, and dairy processors. The ability of L. monocytogenes to survive cold temperatures and its capability to form biofilms as a survival strategy improves its chances of colonising and persisting in 447 food processing environments (Pang, Wong, Chung, \& Yuk, 2019). The colonisation and persistence 448 of L. monocytogenes in food processing plants have been well established in dairy (Melero et al., 449 2019), meat and poultry (Berrang, Meinersmann, Frank, \& Ladely, 2010), fish (Di Ciccio et al., 2012; 
facilities (Henriques, da Gama, \& Fraqueza, 2014). In most colonisation incidences, raw product is an important source of the organism (Berrang et al., 2010; Di Ciccio, et al., 2012; Zuber et al., 2019). Although raw material is an important source of contamination, Di Ciccio et al. (2012) found that contamination of processed food such as smoked salmon occurred mainly during processing rather than from raw materials. GMP failures, equipment design and lack of hygienic measures contribute to the spread and prevalence of $L$. monocytogenes throughout food processing plants. Harbourage sites play a role in the persistence of $L$. monocytogenes as cleaning and sanitising agents are unable to reach sheltered processing areas due unhygienic design of equipment and premises or unhygienic or damaged material (Carpentier \& Cerf, 2011). Lack of hygienic barriers and uncontrolled personnel flow (Melero et al., 2019), spread of contamination by mobile food transport elements (e.g. trolleys, conveyors, forklift trucks) and ineffective hygiene measurements in food contact environments (Muhterem-Uyar et al., 2015), poor food handling after processing (Henriques et al., 2014), inadequate refrigeration temperature and condensation drip from chills on products (Rotariu et al., 2014) are examples of poor GMP and hygienic measures that led to the persistence and contamination of food products. Further root cause analyses were carried out to identify how the failures could have occurred.

Root cause analysis of undeclared allergens and cross contamination

Fishbone diagrams, also known as cause and effect diagrams, or Ishikawa analysis (Ishikawa, 1990) are a problem solving tool in determining root causes of issues. The technique was used to illustrate the root cause analysis (RCA) of undeclared allergens (Figure S2) and cross contamination (Figure S3), where the skeletons represent the different major causal factor categories and primary and secondary causes are organised under these categories. The fishbone diagram is a useful way of organising information, especially when presented with a complex situation (e.g. multiple potential causes) to understand the relationships between the cause and effect (Motarjemi \& Wallace, 2014) and these are often constructed by brainstorming possible causes of a given problem. In this study, the diagrams were developed by grouping the contributory factors identified in the review of official databases and journal articles under appropriate major causal factor categories. Primary causes came from review of official databases and journal articles while secondary causes were derived from literature searches and the Ishikawa cause and effect analysis. 
are portrayed, and this can assist food manufacturers to work back to the root cause. For example, presence of allergens could be due to carry over or cross contact from processing equipment. The cross contact could have occurred due to poor equipment design (e.g. allowing allergen residue to accumulate), ineffective cleaning and sanitation (e.g. inadequate removal of allergen residue) and/or limited product scheduling (e.g. production of allergen containing food followed by non-allergen containing food products on shared equipment) (Dzwolak et al., 2017; Gojkovic et al., 2015; Shoji \& Obata, 2010). Latent and active failures relating to management of people is essential in root cause analysis. Behind any process and control measure, there are staff who have to implement the process / measures or to verify that the measures have been implemented correctly. For example, during labelling of food products, steps are carried out to label and package the product and there are verification steps to ensure that correct labelling / packaging and products are used. Failures to perform such tasks are known as active failures since the (lack of / incorrect) actions have a direct impact on the safety of the products (Motarjemi \& Wallace, 2014). In RCA, investigators should dig deeper and understand the conditions contributing to ineffective cleaning or mislabelling. For example, why was the cleaning inadequate? Are the staff adequately trained? Is sufficient time and resources provided for cleaning? A working environment that leads to non-compliances are latent conditions that arise from management decisions and culture (Motarjemi \& Wallace, 2014).

The causes for cross contamination are divided into five categories i.e. pre-harvest, processing, product, people and place (environment) (Figure S3). Similarly, by applying RCA of the causes, one could evaluate the conditions leading to the incidents. For example, why and how did the cross contamination from food contact surfaces to food product occur? Why were the food contact surfaces contaminated? Did the food handlers cause and/or spread the contamination? As described in the RCA scenario for undeclared allergens, this often leads back to identification of active and latent failures. Failure of food handlers to clean food contact surfaces adequately is an example of active failure. This may be caused by latent failures i.e. the working conditions such as unhygienic equipment design and lack of hygiene barriers or measurements that led to ineffective cleaning and sanitation practices. Latent failures may not have an immediate impact on food safety but create gaps in the food safety management systems and opportunities for active failures and incidents

514 (Motarjemi \& Wallace, 2014). In fact, a combination of active and latent failures often leads to food

515 safety incidents. For example, the culmination of active and latent failures such as an insufficient 516 feedback mechanism, failure of regulators and industrial departments to collect samples, lack of supervision from the Ministry of Health and distributors and retailers making wrong judgements and selling unsafe dairy products led to the melamine in milk incident in 2008 (Song, Yu, \& Lv, 2018). 
Root cause analysis is a practical and useful tool in identifying the actual cause of the incident. Once the root cause is identified, corrective and preventative measures can be implemented to prevent similar incidents from recurring. Thus, food manufacturers could use these Fishbone diagrams (Figures S2 and S3) as guidance on areas to target in continuous improvement programmes to prevent incidents associated with undeclared allergens and cross contamination.

\section{Limitations}

This study is focused on reported food safety incidents, especially incidents where the contributory factors had been identified or suspected at processing facilities. Hence, there remains some discrepancy between the notifications of hazards (e.g. very few Campylobacter incidents) in comparison to regional reports of foodborne illnesses (e.g. Campylobacteriosis is the leading cause of foodborne illness in the EU). There are multiple official websites that could be reviewed such as those from Asia, South America and Africa. This study only includes official websites and journal articles presented in the English language. It is recommended that other official websites particularly those from Asia, South America and Africa are reviewed to determine the trend of global food safety incidents and factors leading to the incidents. The data from RASFF were not reviewed in depth, but future studies could analyse the trends and causative factors for these recalls. It is possible that RASFF is double counting some of the incidents in the 2932 data but this cannot be established without line by line check and this was not possible in the current study. This study is also based on a systematic search and review process and is not as exhaustive compared to the gold standard systematic review. As this form of review does not adhere to a specific guideline, the study did not include a quality assessment to determine inclusion/exclusion of data. However, official data from governmental websites provide the most accurate records of food recalls and incidents and quality of data is assured.

\section{Conclusions}

This study offers key insights into global food safety incidents according to food and drink categories, hazards and common contributory factors. Food incidents are recorded across all 18 BRC food and drink categories with the top three being raw fish, ready-to-eat meals and fruits, vegetables and nuts, making up $43 \%$ of the total 8914 incidents (including RASFF summary data). There has been a doubling of incidents recorded in these sources between 2008 and 2018 but the apparent jump in numbers in 2014 is likely due to a change in recording methodology. Incidents involve all four hazard categories (biological, chemical, physical, allergen) but majority are in allergens and microbiological categories. Cross contamination (microbiological) and undeclared allergens were the most 
frequently cited causes of specific incidents, making up $69 \%$ of the total. In incidents where overall causes were recorded, these were reasonably well detailed ( $n=2932$ incidents). However there is still very limited information recorded on the root causes. Some categories have slightly better information, e.g. equipment design has several specific causes detailed; however, this still does not get to the root cause of the problem, i.e. we still don't know the reasoning behind the plastic pieces, etc., gaining access to the products. Microbiological outbreaks are often investigated in detail to determine the implicated food and sources of contamination e.g. raw materials and/or processing environment. Similarly, it is difficult to identify the root cause of the problem i.e. how did the contaminated raw material contaminate the processing environment or how did the pre-harvest conditions contaminate the food products. Therefore, it is important to examine a range of incidents in depth from a qualitative perspective in order to try to close this data gap that is essential to identify the root causes of the food safety incidents. One of the main contributions and novel findings of this review is the identification of the primary and secondary causes for undeclared allergens and cross contamination. Trend analysis of product notifications and root cause analysis will benefit food regulators and industry by providing guidance on areas of focus for the prevention of incidents.

\section{Acknowledgements}

The authors are grateful to British Retail Consortium for funding the study and for sponsoring Anna Kate May Brazier as the intern for the project.

\section{References}

Alegbeleye, O. O., Singleton, I., \& Sant'Ana, A. S. (2018). Sources and contamination routes of microbial pathogens to fresh produce during field cultivation: A review. Food Microbiology, 73, 177208.

Batz M. B., Hoffmann, S., \& Morris, J. G. Jr. (2012). Ranking the disease burden of 14 pathogens in food sources in the United States using attribution data from outbreak investigations and expert elicitation. Journal of Food Protection, 75(7), 1278-1291.

Bedford, B., Yu, Y., Wang, X., Garber, E. A. E., \& Jackson, L. S. (2017). A limited survey of dark chocolate bars obtained in the United States for undeclared milk and peanut allergens. Journal of Food Protection, 80(4), 692-702.

Behravesh, C. B., Mody, R. K., Jungk, J., Gaul, L., Redd, J. T., Chen, S. et al. (2011). 2008 outbreak of Salmonella Saintpaul infections associated with raw produce. New England Journal of Medicine, 364, 918-927.

Berrang, M. E., Meinersmann, R. J., Frank, J. F., \& Ladely, S. R. (2010). Colonization of a newly constructed commercial chicken further processing plant with Listeria monocytogenes. Journal of Food Protection, 73(2), 286-291. 
Boatemaa, S., Barney, M., Drimie, S., Harper, J., Korsten, L., \& Pereira, L. (2019). Awakening from the listeriosis crisis: Food safety challenges, practices and governance in the food retail sector in South Africa. Food Control, 104, 333-342.

Bonsignore, M., Manta, D. S., Mirto, S., Quinci, E. M., Ape, F., Montalto, V., Gristina, M., Traina, A. and Sprovieri, M. (2018). Bioaccumulation of heavy metals in fish, crustaceans, molluscs and echinoderms from the Tuscany coast. Ecotoxicology and Environmental Safety, 162, 554-562.

Bouzembrak, Y. \& Marvin, H. J. P. (2016). Prediction of food fraud type using data from Rapid Alert System for Food and Feed (RASFF) and Bayesian network modelling. Food Control, 61, 180-187.

Bouzembrak, Y. \& Marvin, H. J. P. (2019). Impact of drivers of change, including climatic factors, on the occurrence of chemical food safety hazards in fruits and vegetables: A Bayesian Network approach. Food Control, 97, 67-76.

BRC (2015). Food safety. A global view 2015. London: BRC Global Standards, pp. 1-48. Available at: https://www.brcglobalstandards.com/media/9393/food-safety-a-global-view-2015.pdf [Accessed 14 February 2019].

Bucchini, L., Guzzon, A., Poms, R., \& Senyuva, H. (2016). Analysis and critical comparison of food allergen recalls from the European Union, USA, Canada, Hong Kong, Australia and New Zealand. Food Additives \& Contaminants: Part A, 33(5), 760-771.

Buchanan, R. L., Gorris, L. B. M., Hayman, M. M., Jackson, T. C., \& Whiting, R. C. (2017). A review of Listeria monocytogenes: An update on outbreaks, virulence, dose-response, ecology, and risk assessments. Food Control, 75, 1-13.

CAC (Codex Alimentarius Commission) (2003). Hazard Analysis and Critical Control Point (HACCP) System and Guidelines for its application. Codex Alimentarius Commission Food Hygiene Basic Texts (Revision 4). Available at: http://www.codexalimentarius.org [Accessed 23 May 2019]

Carpentier, B. \& Cerf, O. (2011). Review - Persistene of Listeria monocytogenes in food industry equipment and premises. International Journal of Food Microbiology, 145(1), 1-8.

Cassin, M. H., Lammerding, A. M., Todd, E. C. D., Ross, W., \& McColl, R. S. (1998). Quantitative risk assessment for Escherichia coli 0157:H7 in ground beef hamburgers. International Journal of Food Microbiology, 41(1), 21-44.

CDC (2009). Multistate Outbreak of Salmonella Typhimurium Infections Linked to Peanut Butter, 2008-2009 (FINAL UPDATE). Available at: https://www.cdc.gov/salmonella/2009/peanut-butter2008-2009.html

CDC (2016). Escherichia coli 0157 infections linked to Jack \& The Green sprouts alfalfa sprouts. Available at: https://www.cdc.gov/ecoli/2016/o157-02-16/index.html [Accessed 22 February 2019]

CDC (2018a). Outbreak of E. coli infections linked to ground beef. Available at: https://www.cdc.gov/ecoli/2018/o26-09-18/index.html [Accessed 20 February 2019]

CDC (2018b). FoodNet 2018 preliminary data. Available at:

https://www.cdc.gov/foodnet/reports/prelim-data-intro-2018.html [Accessed 23 May 2019] 
CDC (2019a). Morbidity and Mortality Weekly Report. Available at: https://www.cdc.gov/mmwr/mmwr_wk/wk_pvol.html [Accessed 8 February 2019]

CDC (2019b). List of selected multistate foodborne outbreak investigations. Available at: https://www.cdc.gov/foodsafety/outbreaks/multistate-outbreaks/outbreaks-list.html [Accessed 8 February 2019]

CDC (2019c). Outbreak of E. coli infections linked to romaine lettuce. Available at: https://www.cdc.gov/ecoli/2018/o157h7-11-18/index.html [Accessed 22 February 2019]

CFIA (2008). Allergy alert. Presence of cashews in some Berni brand pesto. Canadian Food Inspection Agency. Available at: http://epe.lac-bac.gc.ca/100/206/301/cfia-acia/2011-09-

21/www.inspection.gc.ca/english/corpaffr/recarapp/2008/20080522e.shtml [Accessed 20 February 2019]

CFIA (2008). Allergy alert. Undeclared egg in Kellogg's Rice Krispies treats holiday village kits sold at Michaels stores. Canadian Food Inspection Agency. Available at: http://epe.lacbac.gc.ca/100/206/301/cfia-acia/2011-09-

21/www.inspection.gc.ca/english/corpaffr/recarapp/2010/20101223e.shtml [Accessed 20 February 2019]

CFIA (2019). Complete listing of all recalls and allergy alerts. Canadian Food Inspection Agency. Available at: http://www.inspection.gc.ca/about-the-cfia/newsroom/food-recallwarnings/complete-listing/eng/1351519587174/1351519588221 ?ay $=2014 \& f r=0 \& f c=0 \& f d=0 \& f t=1$ [Accessed 8 February 2019]

Colli, L. F. M., da Silva, L. C. R., de Sousa, V. P., de Padula, M., \& Cabral, L. M. (2019). Evaluation of the effectiveness of the notification process in the area of health products. Health Policy and Technology, 8(2), 105-110.

Crim, S. M., Griffin, P. M., Tauxe, R., Marder, E. P., Gilliss, D., Cronquist, A. B. et al. (2015). Preliminary incidence and trends of infection with pathogens transmitted commonly through food Foodborne Diseases Active Surveillance Network, 10 US sites, 2006-2014. MMWR Morbidity and Mortality Weekly Report, 64(18), 495-499.

Domingues, A. R., Pires, S. M., Halasa, T., \& Hald, T. (2012). Source attribution of human campylobacteriosis using a meta-analysis of case-control studies of sporadic infections. Epidemiology \& Infection, 140(6), 970-981.

D.'Amico, P., Nucera, D., Guardone, L., Mariotti, M., Nuvoloni, R., \& Armani, A. (2018). Seafood products notifications in the EU Rapid Alert System for Food and Feed (RASFF) database: Data analysis during the period 2011-2015. Food Control, 93, 241-250.

Da Silva Felicio, M. T., Hald, T., Liebana, E., Allende, A., Hugas, M., Nguyen-The, C., Johannessen, G. S., Niskanen, T., Uyttendaele, M., \& McLauchlin, J. (2015). Risk ranking of pathogens in ready-to-eat unprocessed foods of non-animal origin (FoNAO) in the EU: Initial evaluation using outbreak data (2007-2011). International Journal of Food Microbiology, 195, 9-19. 
Dey, M., Mayo, J. A., Saville, D., Wolyniak, C., \& Klontz, K. C. (2013). Recalls of foods due to microbiological contamination classified by the US Food and Drug Administration, fiscal years 2003 through 2011. Journal of Food Protection, 76(6), 932-938.

Di Ciccio, P., Meloni, D., Festino, A. R., Conter, M., Zanardi, E., Ghidini, S. et al. (2012). Longitudinal study on the sources of Listeria monocytogenes contamination in cold-smoked salmon and its processing environment in Italy. International Journal of Food Microbiology, 158(1), 79-84.

Djekic, I., Jankovic, D., \& Rajkovic, A. (2017). Analysis of foreign bodies present in European food usign data from Rapid Alert System for Food and Feed (RASFF). Food Control, 79, 143-149

Dzwolak, W. (2017). Assessment of food allergen management in small food facilities. Food Control, 73, 323-331.

ECDC (2018a). Rapid risk assessment: Multi-country outbreak of Listeria monocytogenes serogroup $\mathrm{IVb}$, multi-locus sequence type 6 , infections linked to frozen corn and possibly to other frozen vegetables. European Centre for Disease Prevention and Control. Available at:

https://ecdc.europa.eu/en/publications-data/rapid-risk-assessment-multi-country-outbreak-listeriamonocytogenes-serogroup-ivb [Accessed 8 February 2019]

ECDC (2018b). Frozen corn likely source of ongoing Listeria monocytogenes outbreak. European Centre for Disease Prevention and Control. Available at: https://ecdc.europa.eu/en/newsevents/frozen-corn-likely-source-ongoing-listeria-monocytogenes-outbreak [Accessed 8 February 2019]

ECDC (2019). Publications and data. European Centre for Disease Prevention and Control. Available at: https://ecdc.europa.eu/en/publications-data [Accessed 8 February 2019]

ECDC-EFSA (2018). Multi-country outbreak of Listeria monocytogenes serogroup IVb, multi-locus sequence type 6 , infections probably linked to frozen corn. Joint ECDC-EFSA Rapid Outbreak Assessment. Available at: https://ecdc.europa.eu/sites/portal/files/documents/22-02-2018-RRAListeria-Finland.pdf [Accessed 8 February 2019]

EFSA (2015). The European Union summary report on trends and sources of zoonoses, zoonotic agents and foodborne outbreaks in 2013. EFSA Journal, 13(1), DOI: 10.2903/j.efsa.2015.3991

EFSA (2018). The European Union summary report on trends and sources of zoonoses, zoonotic agents and foodborne outbreaks in 2017. EFSA Journal, 16(12), DOI: 10.2903/j.efsa.2018.5500

Erikson, M. C., Liao, J.-Y., Payton, A. S., Cook, P. W., Den Bakker, H. C., Bautista, J., \& Perez, J. C. D. (2019). Pre-harvest internalization and surface survival of Salmonella and Escherichia coli O157:H7 sprayed onto different lettuce cultivars under field and growth conditions. International Journal of Food Microbiology, 291, 197-204.

Flynn, D. (2016). How did Salmonella Hvittingfoss get on Aussie rock melons? Food Safety News. Available at: https://www.foodsafetynews.com/2016/08/130219/\#.WA6FuotMqUk [Accessed 22 February 2019]

FoodNet (2018). Foodborne Diseases Active Surveillance Network. Centers for Disease Control and Prevention. Available at: https://www.cdc.gov/foodnet/index.html [Accessed 15 February 2019] 
FSA (n.d.). Alerts. Food Standards Agency. Available at: https://www.food.gov.uk/newsalerts/search/alerts [Accessed 8 February 2019]

FSAI (2013). FSAl survey finds horse DNA on some beef burger products. Food Safety Authority of Ireland. Available at: https://www.fsai.ie/details.aspx?id=11878 [Accessed 24 October 2019]

FSANZ (2019). Food recalls. Available at:

http://www.foodstandards.gov.au/industry/foodrecalls/recalls/Pages/default.aspx [Accessed 8 February 2019]

FSN (2014). ND firm recalls beef franks for misbranding, undeclared allergen. Food Safety News. Available at: https://www.foodsafetynews.com/2014/01/nd-firm-recalls-beef-franks-formisbranding-undeclared-allergen/\#more-83320 [Accessed 20 February 2019]

Gandhi, M., \& Chikindas, M. L. (2007). Listeria: A foodborne pathogen that knows how to survive. International Journal of Food Microbiology, 113(1), 1-15.

Gaulin, C., Ramsay, D., Catford, A., \& Bekal, S. (2015). Escherichia coli 0157:H7 outbreak associated with the consumption of beef and veal tartares in the Province of Quebec, Canada in 2013. Foodborne Pathogen and Disease, 12(7), 612-618.

Gelting, R., Baloch, M. A., Zarate-Bermudez, M. A., \& Selman, C. (2011). Irrigation water issues potentially related to the 2006 multistate $E$. coli 0157:H7 outbreak associated with spinach. Agricultural Water Management, 98(9), 1395-1402.

Gendel, S. M., \& Zhu, J. (2013). Analysis of U.S. Food and Drug Administration food allergen recalls after implementation of the Food Allergen Labeling and Consumer Protection Act. Journal of Food Protection, 76(11), 1933-1938.

Gojkovic, V., Marjanovic-Balaban, Z., Vukic, M., Grujic, R., \& Novakovic, B. (2015). Allergen management system in the food production. Journal of Hygienic Engineering and Design, 12, 76-84.

Grant, M. J., \& Booth, A. (2009). A typology of reviews: an analysis of 14 review types and associated methodologies. Health Information and Libraries Journal, 26, 91-108.

Henriques, A. R., de Gama, L. T., \& Fraqueza, M. J. (2014). Assessing Listeria monocytogenes presence in Portuguese ready-to-eat meat processing industries based on hygienic and safety audit. Food Research International, 63(Part A), 81-88.

Hola, B., Nowobilski, T., Szer, I., \& Szer, J. (2017). Identification of factors affecting the accident rate in the construction industry. Procedia Engineering, 208, 35-42.

Ishikawa, K. (1990). Introduction to Quality Control, Productivity Press, New York.

Jacobsen, C. S. \& Bech, T. B. (2012). Soil survival of Salmonella and transfer to freshwater and fresh produce. Food Research International, 45(2), 557-566.

Julien-Javaux, F., Gerard, C., Campagnoli, M., \& Zuber, S. (in press). Strategies for the safety management of fresh produce from farm to fork. Current Opinion in Food Science. DOI: 10.1016/j.cofs.2019.01.004 
Kase, J. A., Zhang, G., \& Chen, Y. (2017). Recent foodborne outbreaks in the United States linked to atypical vehicles - lessons learned. Current Opinion in Food Science, 18, 56-63.

Keller, S. E., VanDoren, J. M., Grasso, E. M., \& Halik, L. A. (2013). Growth and survival of Salmonella in ground black pepper (Piper nigrum). Food Microbiology, 34(1), 182-188.

Kleter, G. A., Prandini, A., Filippi, L., \& Marvin, H. J. P. (2009). Identification of potentially emerging food safety issues by analysis of reports published by the European Community's Rapid Alert System for Food and Feed (RASFF) during a four-year period. Food and Chemical Toxicology, 47(5), 932-950.

Lake, I. R., Colon-Gonzalez, F. J., Takkinen, J., Rossi, M., Sudre, B., Gomes Dias, J. et al. (2019).

Exploring Campylobacter seasonality across Europe using the European Surveillance System (TESSy), 2008 to 2016. Eurosurveillance, 24(13), pii=1800028.

Lambertini, E., Mishra, A., Guo, M., Co, H., Buchanan, R. L., \& Pradhan, A. K. (2016). Modeling the long-term kinetics of Salmonella survival on dry pet food. Food Microbiology, 58, 1-6.

Luth, S., Boone, I., Kleta, S., \& Al Dahouk, S. (2019). Analysis of RASFF notifications on food products contaminated with Listeria monocytogenes reveals options for improvement in the rapid alert system for food and feed. Food Control, 96, 479-487.

Matthews, K. R., Sapers, G. M., \& Gerba, C. P. (2014). The Produce Contamination Problems: Causes and Solutions. Amsterdam: Academic Press, pp. 1- 469.

McCabe-Sellers, B. J., Beattie, S. E. (2004). Food safety: Emerging trends in foodborne illness surveillance and prevention. Journal of the American Dietetic Association, 104(11), 1708-1717.

McCollum, J. T., Cronquist, A. B., Silk, B. J., Jackson, K. S., O'Connor, K. A., Cosgrove, S. et al. (2013). Multistate outbreak of listeriosis associated with cantaloupe. New England Journal of Medicine, 369, 944-953.

Melero, B., Stessl, B., Manso, B., Wagner, M., Esteban-Carbonero, O. J., Hernandez, M., Rovira, J., \& Rodriguez-Lazaro, D. (2019). Listeria monocytogenes colonization in a newly established processing facility. International Journal of Food Microbiology, 289, 64-71.

Motarjemi, Y., \& Wallace, C. A. (2014). Food safety assurance systems: Root cause analysis of incidents. Y. Motarjemi, G. Moy \& E. Todd (Eds.). Encyclopedia of Food Safety, Volume 4. San Diego: Academic Press, 331-339.

Muhterem-Uyar, M., Dalmasso, M., Bolocan, A. S., Hernandez, M., Kapetanakou, A. E., Kuchta, T. et al. (2015). Environmental sampling for Listeria monocytogenes control in food processing facilities reveals three contamination scenarios. Food Control, 51, 94-107.

Nerin, C., Aznar, M., \& Carrizo, D. (2016). Food contamination during food process. Trends in Food Science \& Technolohy, 48, 63-68.

Nepusz, T., Petroczi, A., \& Naughton, D. P. (2009). Food alert patterns for metal contamination analyses in seafoods: Longitudinal and geographical perspectives. Environment International, 35(7), 1030-1033. 
NNDSS (2018). National Notifiable Diseases Surveillance System. Centers for Disease Control and Prevention. Available at: https://www.cdc.gov/foodnet/index.html [Accessed 15 February 2019]

Padua, I., Moreira, A., Moreira, P., de Vasconcelos, F. M., \& Barros, R. (2019). Impact of the regulation (EU) 1169/2011: Allergen-related recalls in the rapid alert system for food and feed (RASFF) portal. Food Control, 98, 389-398.

Pang, X., Wong, C., Chung, H.-J., \& Yuk, H.-G-. (2019). Biofilm formation of Listeria monocytogenes and its resistance to quarternary ammonium compounds in a simulated salmon processing environment. Food Control, 98, 200-208.

Paramithiotis, S., Drosinos, E. H., \& Skandamis, P. N. (2017). Food recalls and warnings due to the presence of foodborne pathogens - a focus on fresh fruits, vegetables, dairy and eggs. Current Opinion in Food Science, 18, 71-75.

PHE, Public Health England (2016). E. coli 0157 national outbreak update. Available at: https://www.gov.uk/government/news/update-as-e-coli-o157-investigation-continues [Accessed 22 February 2019]

Piglowski, M. (2018). Heavy metals in notifications of Rapid Alert System for Food and Feed. International Journal of Environment Research and Public Health, 15(2), 365. DOI: 10.3390/ijerph15020365

Potter, A., Murray, J., Lawson, B. \& Graham, S. (2012). Trends in product recalls within the agri-food industry: Empirical evidence from the USA, UK and the Republic of Ireland. Trends in Food Science \& Technology, 28(2), 77-86.

RASFF (n.d.a). RASFF - Food and feed safety alerts. European Commission. Available at: https://ec.europa.eu/food/safety/rasff_en [Accessed 15 February 2019]

RASFF (n.d.b). RASFF portal. European Commission. Available at: https://ec.europa.eu/food/safety/rasff/portal_en [Accessed 18 February 2019]

RASFF (2015). The Rapid Alert System for Food and Feed 2015 Annual Report. Available at: https://ec.europa.eu/food/sites/food/files/safety/docs/rasff_annual_report_2015.pdf [Accessed 8 February 2019]

RASFF (2017). The Rapid Alert System for Food and Feed 2017 Annual Report. Available at: https://ec.europa.eu/food/sites/food/files/safety/docs/rasff_annual_report_2017.pdf [Accessed 8 February 2019]

Ravel, A., Hurst, M., Petrica, N., David, J., Mutschall, S. K., Pintar, K., Taboada, E. N., \& Pollari, F. (2017). Source attribution of human campylobacteriosis at the point of exposure by combining comparative exposure assessment and subtype comparison based on comparative genomic fingerprinting. PLOS ONE, 12(8), e0183790.

Regulation (EU) No. 1169/2011 (2011). Regulation (EU) No 1169/2011 of the European Parliament and of the Council of 25 October 2011. Available at: https://eur-lex.europa.eu/legalcontent/EN/TXT/PDF/?uri=CELEX:32011R1169\&from=EN [Accessed 18 February 2019] 
Rotariu, O., Thomas, J. I., Goodburn, K. E., Hutchinson, M. L., \& Strachan, N. C. (2014). Smoked salmon industry practices and their association with Listeria monocytogenes. Food Control, 35(1), 284-292.

Russo, E. T., Biggerstaff, G., Hoekstra, M., Meyer, S., Patel, N., Miller, B. et al. (2013). A recurrent, multistate outbreak of Salmonella serotype Agona infections associated with dry, unsweetened cereal consumption, United States, 2008. Journal of Food Protection, 76(2), 227-230.

Sheth, A. N., Hoekstra, M., Patel, N., Ewald, G., Lord, C., Clarke, C. et al. (2011). A national outbreak of Salmonella serotype Tennessee infections from contaminated peanut butter: A new food vehicle for salmonellosis in the United States. Clinical Infectious Diseases, 53(4), 356-362.

Shoji, M., \& Obata, T. (2010). Manufacturing a biscuit that does not use milk, eggs, or soybeans. In, Allergen Management in the Food Industry. J. I. Boye \& S. B. Godefroy (Eds.). New Jersey: John Wiley \& Sons, pp. 393-419.

Song, Y.-H., Yu, H.-Q., \& Lv, W. (2018). Risk analysis of dairy safety incidents in China. Food Control, 92, 63-71.

Swaminathan, B., Cabanes, D., Zhang, W., \& Cossart, P. (2007). Listeria monocytogenes. In, Food Microbiolog: Fundamentals and Frontiers. M. P. Doyle, \& L. R. Beuchat (Eds.). $3^{\text {rd }}$ Edition. Washington D.C.: ASM Press, pp. 457-491.

Tähkäpää, S., Maijala, R., Korkeala, H. \& Nevas, M. 2015. Patterns of food frauds and adulterations reported in the EU rapid alert system for food and feed and in Finland. Food Control, 47, 175-184.

Traina, A., Bono, G., Bonsignore, M., Falco, F., Giuga, M., Quinci, E. M., Vitale, S., \& Sprovieri, M. (2019). Heavy metals concentrations in some commercially key species from Sicilian coasts (Mediterranean Sea): Potential human health risk estimation. Ecotoxicology and Environmental Safety, 168, 466-478.

Uesugi. A. R., Danyluk, M. D., \& Harris, L. J. (2006). Survival of Salmonella Enteritidis phage type 30 on inoculated almonds stored at $-20,4,23$, and 35ํ․ Journal of Food Protection, 69(8), 1851-1857.

US FDA (2011). Environmental assessment: Factors potentially contributing to the contamination of fresh whole cantaloupe implicated in a multi-state outbreak of listeriosis. US Food and Drug Administration. Available at: http://calcitrusquality.org/wp-content/uploads/FDA-Jensen-FarmsEnvironmental-Assessment-Final-Report.pdf [Accessed 22 February 2019]

USDA FSIS (2016). Boyle's Famous Corned Beef Co. recalls beef products due to misbranding and undeclared allergen. US Department of Agriculture, Food Safety and Inspection Service. Available at: https://www.fsis.usda.gov/wps/portal/fsis/topics/recalls-and-public-health-alerts/recall-casearchive/archive/2015/recall-143-2015-release [Accessed 20 February 2019]

USDA FSIS (2017). Mibo fresh food recalls turkey salad products due to misbranding and undeclared allergens. US Department of Agriculture, Food Safety and Inspection Service. Available at: https://www.fsis.usda.gov/wps/portal/fsis/topics/recalls-and-public-health-alerts/recall-casearchive/archive/2017/recall-034-2017-release [Accessed 20 February 2019] 
USDA FSIS (2018). Recall case archive. US Department of Agriculture, Food Safety and Inspection Service. Available at: https://www.fsis.usda.gov/wps/portal/fsis/topics/recalls-and-public-health-

USFDA (2018a). Archive for recalls, market withdrawals and safety alerts. US Food and Drug Administration. Available at: https://www.fda.gov/Safety/Recalls/ArchiveRecalls/default.htm [Accessed 8 February 2019]

USFDA (2018b). Outbreaks of foodborne illness. US Food and Drug Administration. Available at: https://www.fda.gov/Food/RecallsOutbreaksEmergencies/Outbreaks/default.htm [Accessed 8 February 2019]

Varzakas, T. (2016). HACCP and ISO22000: Risk assessment in conjunction with other food safety tools such as FMEA, Ishikawa diagrams and Pareto. B. Caballero, P. M. Finglas \& F. Toldra (Eds). In, Encyclopedia of Food and Health, , 295-302.

Verhaelen, K., Bouwknegt, M., Rutjes, S. A., \& Husman, A. M. R. (2013). Persistence of human norovirus in reconstituted pesticides - Pesticide application as a possible source of viruses in fresh produce chains. International Journal of Food Microbiology, 160(3), 323-328.

Vierk, K., Falci, K., Wolyniak, C., \& Klontz, K. C. (2002). Recalls of foods containing undeclared allergens reported to the US Food and Drug Administration, fiscal year 1999. Journal of Allergy and Clinical Immunology, 109, 1022-1026.

Wasala, L., Talley, J. L., DeSilva, U., Fletcher, J., \& Wayadande, A. (2013). Transfer of Escherichia coli 0157:H7 o spinach by house flies, Musa domestica (Diptera: Muscidae). Phytopathology, 103(4), 373-380.

Werber, D., Dreesman, J., Feil, F., van Treeck, U., Fell, G., Ethelberg, S. et al. (2005). International outbreak of Salmonella Oranienburg due to German chocolate. BMC Infectious Disases, 5(7), DOI: 10.1186/1471-2334-5-7

Whitworth, J. (2018). South Africa declares end to largest ever Listeria outbreak. Food Safety News. Available at: https://www.foodsafetynews.com/2018/09/south-africa-declares-end-to-largest-everlisteria-outbreak/ [Accessed 8 February 2019]

WHO (2015). WHO estimates of the global burden of foodborne diseases. Foodborne diseases burden epidemiology reference group 2007-2015, World Health Organization. Available at: https://www.who.int/foodsafety/publications/foodborne_disease/fergreport/en/ [Accessed 8 February 2019]

Yahata, Y., Misaki, T., Ishida, Y., Nagira, M., Watahiki, M., Isobe, J. et al. (2015). Epidemiological analysis of a large enterohaemorrhagic Escherichia coli O111 outbreak in Japan associated with haemolytic uraemic syndrome and acute encephalopathy. Epidemiology and Infection, 143(13), 2721-2732.

Yang, X., Wang, H., He, A., \& Tran, F. (2018). Biofilm formation and susceptibility to biocides of recurring and transient Escherichia coli isolated from meat fabrication equipment. Food Control, 90, 205-211. 